\title{
Implementation of Artificial Neural Fuzzy Inference System in a Real Time Fire Detection Mechanism
}

\author{
Divya Sharma \\ Department of Mechanical and \\ Automation Engineering \\ Indira Gandhi Delhi Technical \\ University for Women \\ Delhi, India
}

\author{
Kajal Singh \\ Department of Mechanical and \\ Automation Engineering \\ Indira Gandhi Delhi Technical \\ University for Women \\ Delhi, India
}

\author{
Shipra Aggarwal \\ Department of Mechanical and \\ Automation Engineering \\ Indira Gandhi Delhi Technical \\ University for Women \\ Delhi, India
}

\begin{abstract}
This paper proposes a hardware model that provides new fire detection and control mechanism with the interface of artificial neural network and fuzzy logic. This work is based on the integration of hardware module and implementation of artificial neural fuzzy inference system (ANFIS). The hardware consists of temperature sensor, smoke sensor, flame detector and a microcontroller unit. The sensors sense the environment and send data to microcontroller for further processing. Here the microcontroller will work as a control unit. The hardware model of the system also consists of the GSM module for sending the warning message if severe fire exists, and a GPS module in order to indicate the fire location. This technique expresses the idea of implementing Fuzzy logic on the real time data which is collected by the sensors. The system aims to predict fire danger by sensing various parameters i.e. smoke, temperature etc. at the early stage. Artificial neural fuzzy inference system (ANFIS) has been utilized in order to enhance the reliability and certainty of real time fire detection mechanism and to reduce the false alarm rates. The system will focus on collection of data from sensors, data fusion through fuzzy logic and quantification of fire warning level. This neural network based fire alarm system can fuse a variety of data set obtained from sensors and also provide the improved ability to adapt in the environment and predict fire in an accurate manner, which has great significance for the safety of human lives as well as property.
\end{abstract}

\section{Keywords}

Fire detection, fuzzy inference system, fuzzy logic, data fusion, artificial neural Network (ANN), graphical user interface (GUI)

\section{INTRODUCTION}

Fire is a combustion process which results in light, smoke, heat, flame and various hazardous gases. Heat, oxygen and fuel are the three major elements of fire. The nature of the fire depends on the proportion of each of these elements [1]. Even though the fire has been always useful for promoting the development of human society and it is extensively used in lot of applications such as cooking, manufacturing process and other processes. But when fire is out of control, i.e., fire hazard, it can cause a serious effect to human life as well as property. Fire hazards can also damage the ecological environment on a great level. Fire detection is usually done manually by visual observation but it is a hazardous job that can put the life of a human being in danger. Thus in order to prevent fire hazards and reduce losses due to fire, and for human safety, there is a great requirement to develop an intelligent system which can provide the functions of real time fire detection and control in an automatic manner. By putting these types of automatic systems to perform the fire prediction task in a fire-prone area, it can help in avoiding fire accidents and the loss of lives.

Traditionally the fire detection is done using only smoke detectors which is less reliable technique and results in false alarms and these fire detectors are unable to respond quickly and in reliable manner in hazardous conditions [2]. Unlike the traditional fire detection devices, this system implements a multi sensor approach in predicting the fire. This work is based on the design of a hardware module for automatic fire detection as well as reduction in unwanted and false fire alarm rates by interfacing fuzzy logic approach trained by artificial neural network. Here a multi sensor based intelligent system is proposed using fuzzy logic approach in order to reduce false alarms and increase the reliability of the entire system. This system uses a microcontroller unit with smoke sensor, temperature sensor and flame detector as the detection devices. Compared with existing fire detection systems, this system has many characteristics. With the implementation of data fusion methodology, it can reduce the false alarm rate. The system also helps in reducing the chances of missing fire detection. It can provide continuous monitoring of flammable places and also the fire location can be determined with the help of GPS. With the implementation of ANFIS, the system can easily adapt itself according to the environment. In this system, controlling and monitoring is done by microcontroller unit via different sensors. The system collects the data from sensors and this data is fuzzified and trained by various decision rules using data fusion methodology [7]. Based on these decisions, the system will identify the occurrence of fire conditions. Whenever severe fire conditions occur, this information will be transmitted in the form of a warning message, via GSM module. Also a buzzer is implemented in the system for alert purpose. Whenever sensors values exceed the threshold values stored in the database of microcontroller, then buzzer will be alarmed.

In order to avoid unwanted and missing fire alarms, Sugeno method has been used with artificial neural network in fuzzy logic system. This method provides higher accuracy as compared to traditional Mamdani method [4]. In this method, only raw data is collected and rule base systems are artificially trained with the help of artificial neural network. This is why this system is called as Artificial Neural Fuzzy Inference System. The data, collected from all sensors is fuzzified. Fuzzification is a process of converting the raw values into fuzzy data set with the help of fuzzy linguistic variables and fuzzy membership functions [19]. Linguistic variables are the input or output variables whose values are in form of either words or sentences from any natural language, rather than 
numeric values [19]. After this process, an inference is made based on decision rules. Now the fuzzy output is obtained using the membership functions. This process is called as defuzzification. The basic process of a fuzzy logic system is explained in the Figure 1.

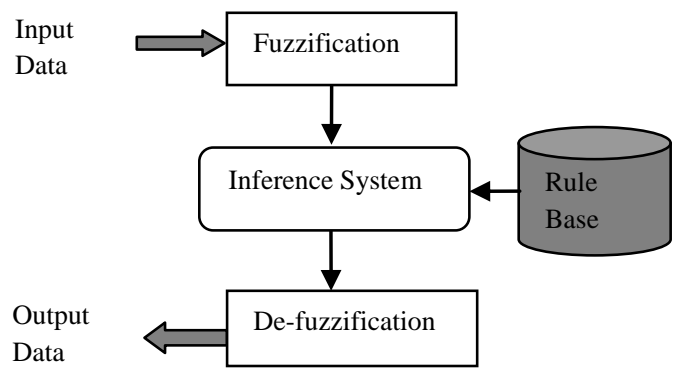

Fig 1: Fuzzy Logic Configuration

\section{LITERATURE REVIEW}

Many technologies have been applied so far in the field of early fire detection mechanism and a lot of research work is going on in the direction to reduce unwanted and false alarm rate. Various techniques have been proposed in literature, which are discussed below:

A multi sensor based hardware module has been designed for fire detection and fuzzy logic is implemented for reduction of false alarms [1]. This fire detection system is made more intelligent by integrating smart extinguisher system. This system is intelligent enough in order to discard deceptive fire situations [2]. Further, a new model was developed that proposed new fire prediction and detection techniques for rural- urban areas. In this approach, video monitoring systems were used for smoke detection [3]. But video monitoring systems are not appropriate enough for fire detection because smoke videos are sometimes misidentified as fire [2]. Therefore, these systems were further modified by implementing neural network approach for early fire detection. This system gathers information about smoke density, temperature and concentration of Carbon-mono-oxide gas in order to determine fire probability [6]. In [7, 11], authors have used information fusion technology for fire detection. Artificial neural network techniques are implemented in the designing of intelligent fire detector with the help of back propagation models. In this system, ANN is used for processing the sensor data [9]. The advanced study has been done on implementation of neural network data fusion algorithm to detect fire [10]. Wireless Sensor Networks (WSNs) have been used in the field of forest fire detection [4, 5]. Multiple sensor nodes have been used for fire detection and then fuzzy logic is implemented on the data collected from sensors.

\section{SYSTEM DESIGN AND DEVELOPMENT}

The development of entire system can be classified into two parts (i) Designing of hardware prototype and its simulation in Proteus software, and (ii) Generating the graphical user interface in Matlab and implementation of ANFIS with the help of fuzzy tool box in Matlab. First the hardware model developed according to block diagram described in Figure 2.

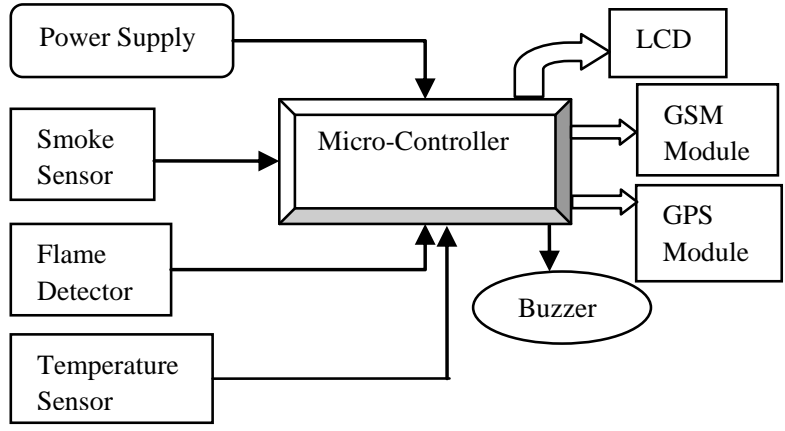

Fig 2: Block Diagram of hardware module of system

\subsection{Description Of Components}

The components of hardware module are detection devices i.e. temperature sensor, flame detector and smoke sensor, controlling unit i.e. microcontroller, output devices i.e. LCD and buzzer and an alert notification system for transmitting warning messages i.e. GSM module. The hardware module also consists of GPS for determining the location of fire place. GPS module indicates the location in terms of longitude and latitude. The brief description of all components is as follows:

\subsubsection{Smoke Sensor}

Smoke Sensor MQ-2 is used in this system for sensing smoke particles. Sensitive material of MQ-2 sensor is tin-di-oxide $\left(\mathrm{SnO}_{2}\right)$. It works on the principle of thermal ionization. When target gas interacts with the external chamber of smoke sensor, the conductivity of sensor is increased according to the gas concentration. This sensor is highly sensitive to LPG, Propane and Hydrogen, and can also be used for sensing combustible gases like methane, butane etc

\subsubsection{Temperature Sensor}

LM- 35 temperature sensor has been used in this module for sensing the temperature. This sensor has a maximum temperature range for $150^{\circ} \mathrm{C}$. It produces an output voltage which is directly proportional to the change in temperature. The operating voltage range of LM-35 temperature sensor is from $4 \mathrm{~V}$ to $30 \mathrm{~V}$. It will produce analog output which is converted in digital form using analog to digital converter.

\subsubsection{Flame Detector}

Flame Detector is used for detecting the presence of fire. It responses to a detected flame depends on the installation of the sensor. Flame detectors sense infrared and ultra violet light radiation. In this system, ultra violet light radiation based flame sensor has been used. They can often respond faster and more accurately than a conventional heat detector due to the mechanism it uses to detect the flame. It can produce output both in analog and digital form.

\subsubsection{ATmega16 Microcontroller Unit}

ATmega 16 is an 8- bit low power AVR microcontroller from Atmel family, having advanced RISC architecture and $16 \mathrm{~Kb}$ internal memory. Its operating voltage range is $4.5-5.5 \mathrm{~V}$. It acts as a control unit in this system, takes the data from sensors and processes this data.

\subsubsection{GSM and GPS Module}

GSM module is used for transmitting the fire alert notifications. It will send the message only when severe fire conditions exist. GPS module is used for indicating the location of fire. It will indicate the location in the terms of longitude and latitude. 


\subsubsection{LCD and Buzzer}

LCD is used for displaying the sensor data and warning messages and a buzzer will be alarmed whenever the sensor values exceed the threshold level.

\subsection{Hardware Module}

The hardware module is developed using an Atmega 16 development board. All sensors and other components like LCD, buzzer, and Bluetooth module have been interfaced to this board for designing hardware module. This Bluetooth is connected to the Bluetooth of PC in order to transfer the data from all the sensors and GPS module, to the GUI which is created in Matlab. This function will enable the real time data transfer from hardware unit to software. Figure 3 represents the hardware module design of the proposed system.

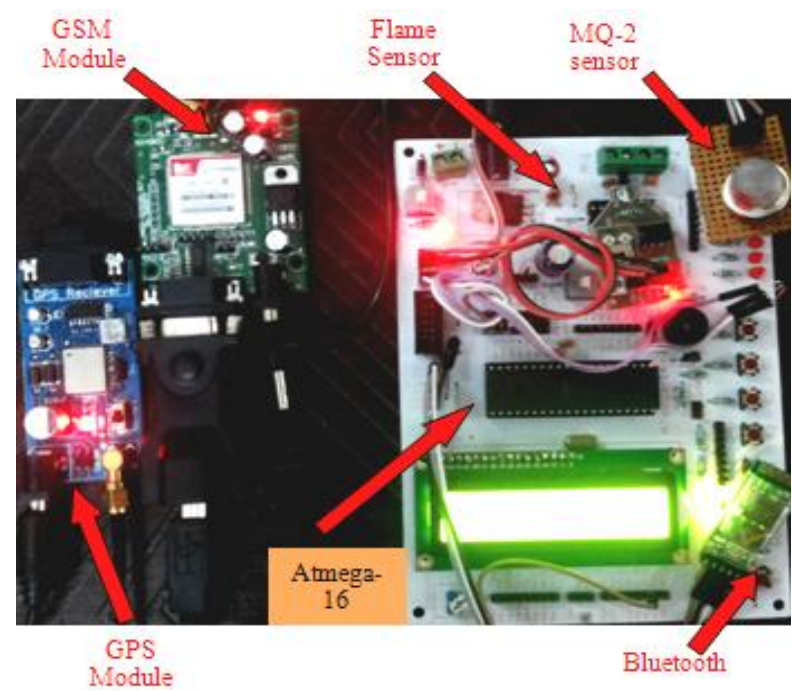

Fig 3: Hardware module design of system

\subsection{Software Simulation of Hardware Module}

The simulation of the hardware prototype has been done in Proteus simulation software. Schematic diagram was created on Proteus and then it was simulated for real time values to analyze the performance of hardware module. The schematic diagram implemented in Proteus software is shown in Figure 4 .

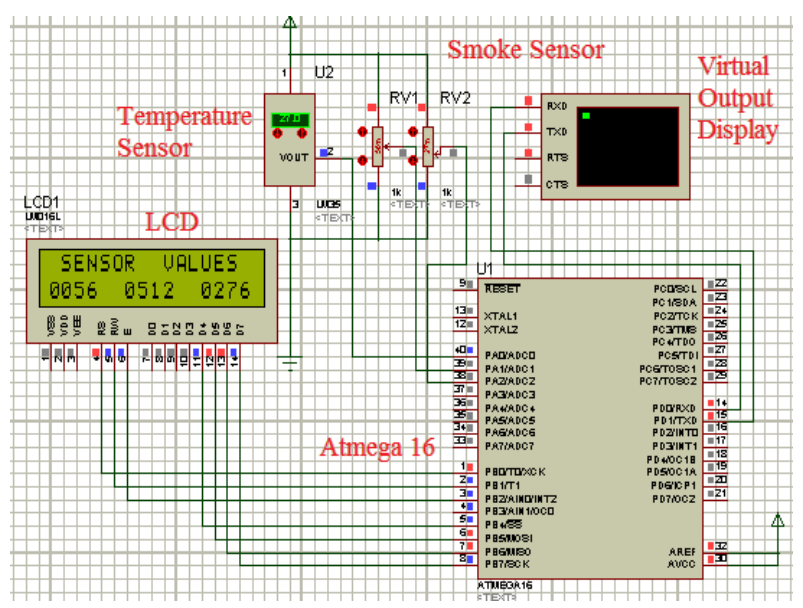

Fig 4: System schematic implemented in Proteus Simulation Software

\section{METHODOLOGY}

The reliability and accuracy of this system will greatly depend on the sensors and data fusion algorithm which is used for the reduction of false fire alarms. To ensure reliability, we have used three different types of sensors which sense all the parameters resulting fire conditions. This system works in the two manners. First, the hardware module will start working. Sensors senses the parameters and produce data which is further processed by controller. Whenever the sensors values exceed the predetermined values stored in the database of the controller, the buzzer will be alarmed. This procedure will help in the early prediction of fire.

Now, the second part of the system will start working. In this approach, first of all the raw data is collected from all the three sensors which are the real time values as sensed by the sensors. Now, a graphical user interface (GUI) is created in Matlab. In this GUI, all real time values are displayed. Now this data is concatenated and fuzzified. Since the system is trained by ANN, it will automatically generate all decision rules according to the value of input data. A lot of rule base are generated depending on various combination of input data obtained from sensors. Based on these rule bases, the system will identify the real or false fire alarms. This system is intelligent enough to adapt itself according to the data which is coming from all three sensors as it is trained by ANN. After the defuzzification process, output is obtained which is either constant or linear in the Sugeno method. For this system, we have categorized the output in three categories i.e. No Fire, Potential Fire and Severe Fire. With the help of data fusion algorithm, trained by ANFIS, the system will identify the severe fire conditions. Now, if severe fire conditions exist, the command will be sent to the controller and a warning message is transmitted through GSM Module. This information also contains the fire location in the form of longitude and latitude. This is done with the help of GPS module. Thus this system will always make sure that people should be informed as soon as severe fire conditions are detected. Figure 5 represents the fuzzy logic implementation in this technique.

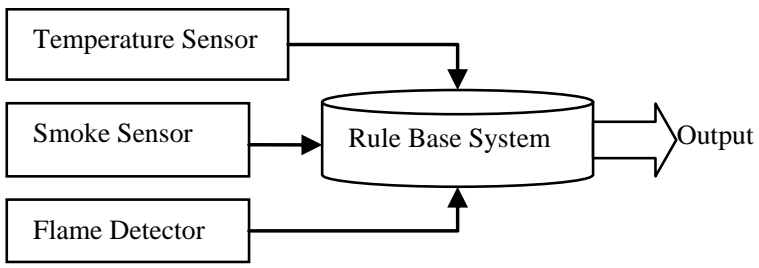

Fig 5: Interfacing of Fuzzy logic in the system

A method for verification of alarm has been also utilized in this system. Whenever the sensor senses any possible fire event, the system checks the risk of fire danger before alarming. If the risk level is above than the normal level only then alarm will be triggered otherwise the system considers this situation as a false detection.

\subsection{ANFIS Implementation in the System}

Implementation of ANFIS makes this system intelligent. ANFIS is the integration of fuzzy logic system which is artificially trained by neural networks. For implementation of fuzzy logic in this system, Sugeno method of fuzzy logic has been used for high accuracy and reliability. For this method, first linguistic variables are created for raw data. These variables are represented as a set of linguistic terms. Here, three input variables have been used and each input is further represented as a set of three linguistic terms i.e. for input variable temperature, three linguistic terms are defined as low, 
normal and high. Similarly for second input variable flame, linguistic terms are defined as no flame, moderate flame and severe flame. Also for third input variable smoke, three linguistic terms have been defined which are no smoke, moderate smoke and severe smoke.

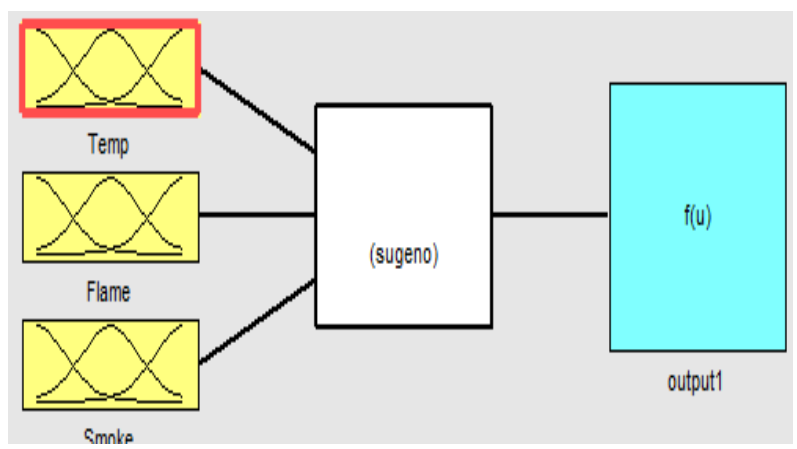

Fig 6: Fuzzy Inference System

Figure 6 explains how a data file is created in sugeno with the help of membership functions of all input variables. This data file represents data fusion methodology. Now, the membership functions are created for all input variables. These are used in the fuzzification and defuzzification process of an ANFIS system in order to map the non fuzzy values to various linguistic terms and vice-versa. These functions may be in various forms like trapezoidal, triangular, Gaussian etc. Gaussian and triangular are the mostly used forms of membership functions. In this system, membership functions have been used in the Gaussian form. Figures 7, 8 and 9 show the Gaussian membership functions for all three inputs i.e. temperature, flame and smoke respectively.

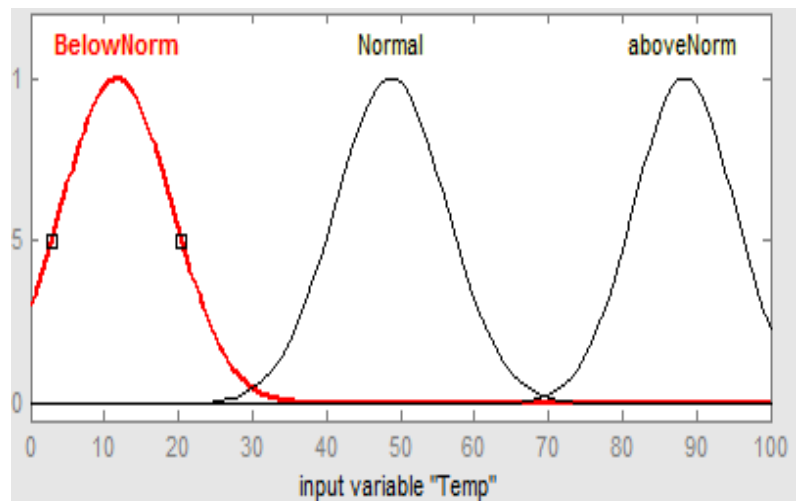

Fig 7: Membership function for Input variable "Temperature"

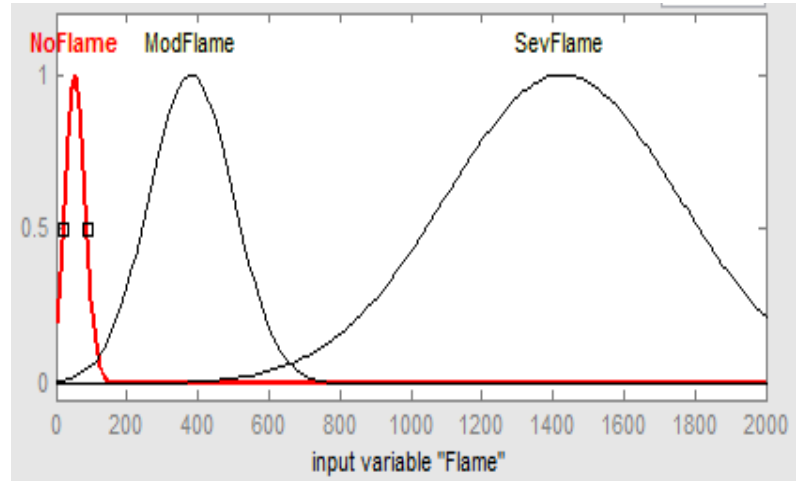

Fig 8: Membership function for Input variable "Flame"

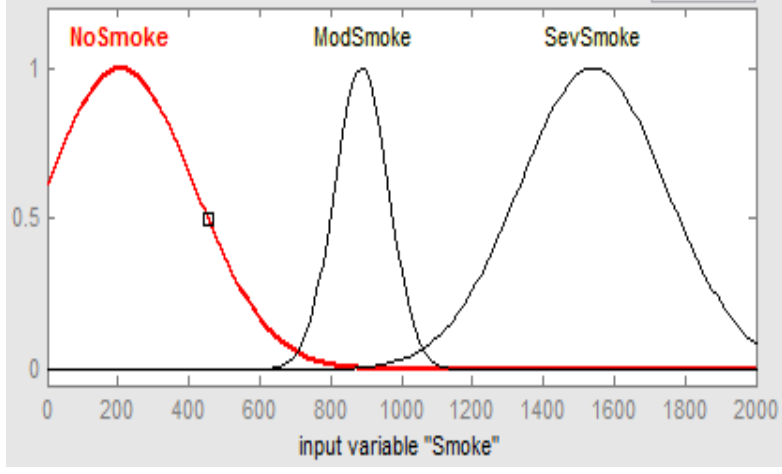

Fig 9: Membership function for Input variable "Smoke"

Now, the fuzzy rule base is created in order to obtain the desired output. Fuzzy rules are simple rules based on If- Then statement and some conditions which result in some conclusions. The evaluation of all fuzzy rules is done by using AND or OR operators on all fuzzy sets. Now, the results from all fuzzy rules are evaluated and after evaluation these results are combined to obtain a final result. This process is known as Inference. The obtained result is a fuzzy value which is now defuzzified in order to obtain final output value. This process is called defuzzification, which is performed on the basis of membership function of output. Figure 10 represents the structure of entire process implementation with the rule base. This structure also represents the mapping of all input membership functions over output with the help of fuzzy rules. There are three input nodes and an output node obtained with the help of various decision rules.

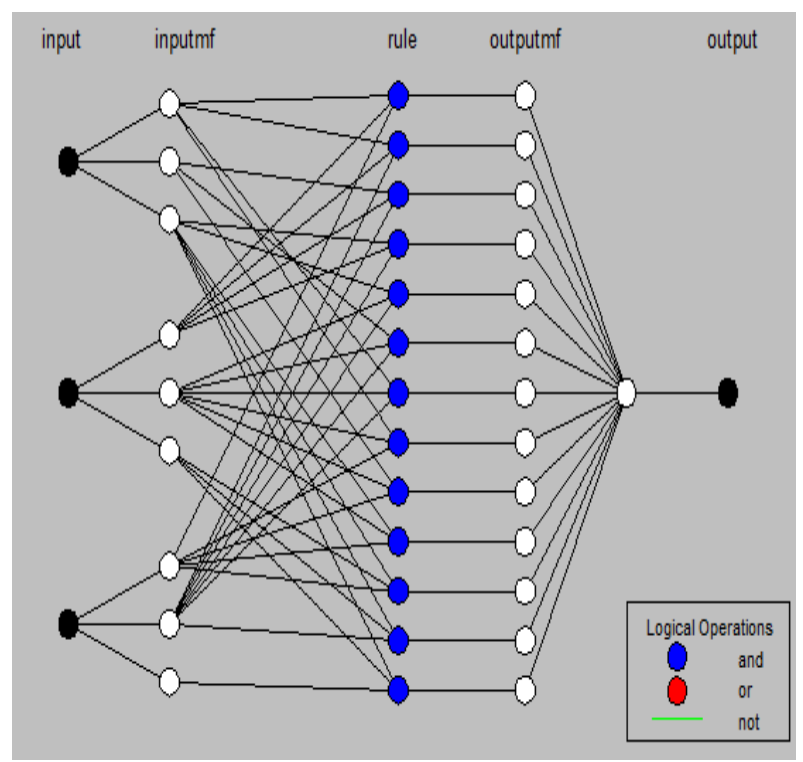

Fig 10: Fuzzy rule base structure

\subsection{Fire Detection Flow Diagram with Implementation of Fuzzy Logic}

The flow process of overall system including the data collection and data fusion is represented in the following flow diagram. The function of system is to perform continuously monitoring. Whenever the system detects no fire conditions, the controlling unit takes no action and if potential fire conditions are detected then buzzer is alarmed. If severe fire is detected only then notifications are sent via GSM module. 


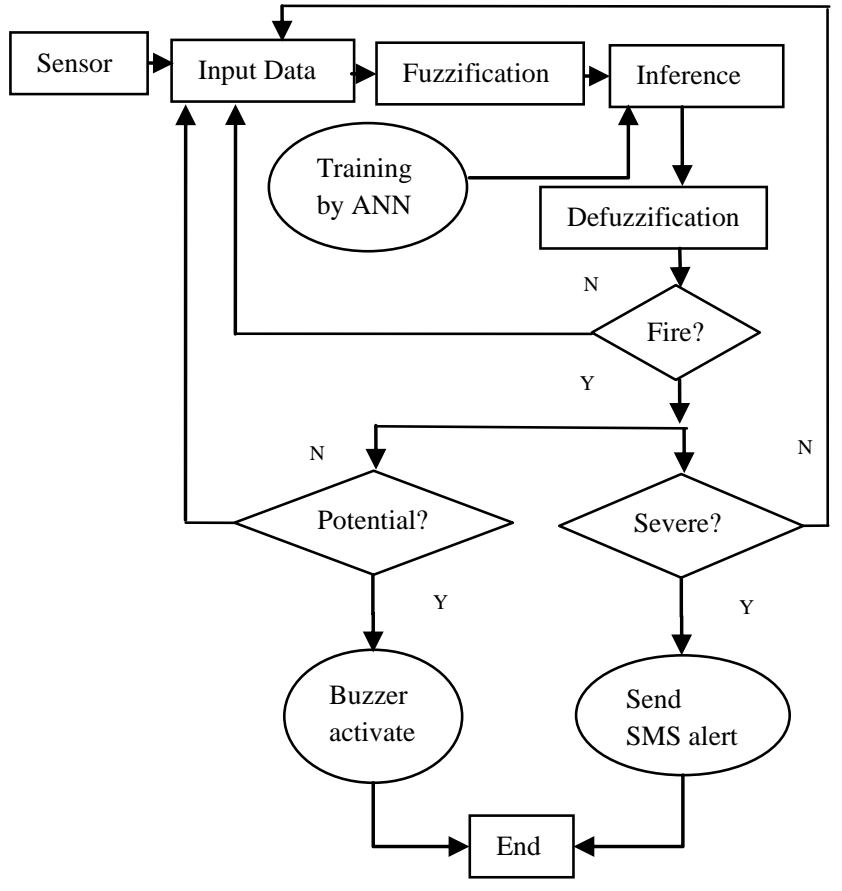

Fig 11: Flow Diagram of System Implementation

\section{RESULTS AND ANALYSIS}

Various experiments were conducted in the presence of smoke and flame. It was observed that with all three states of output, the system gives fire alerts notifications only when there is either potential fire or severe fire depending on all the rules thus reducing the false fire alarm rate. Results of experimental analysis are shown in Figure 12, which represents the scale of fire probability.

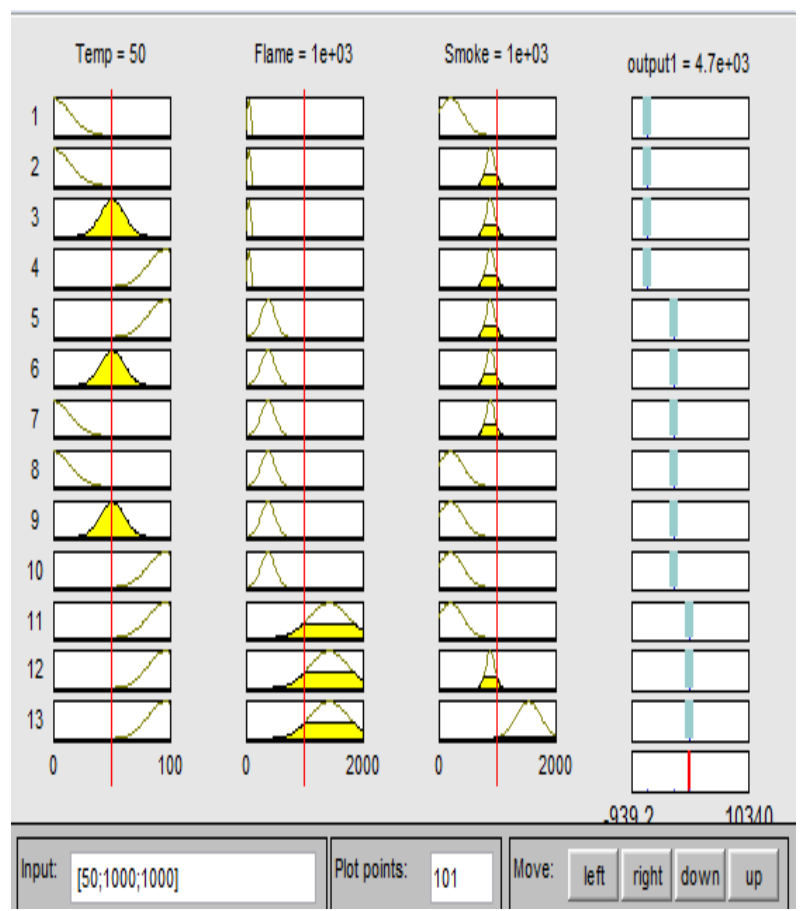

Fig 12: Fire probabilities based on Rule Base

The scale represents that probability of occurring of fire conditions increases when any of the sensor data reaches above the threshold values. For output conditions, three conditions have been described which are no fire, potential fire and severe fire. In the given fire probability scales, whenever any of the input data is increased or decreased, the output is affected and resulting fire probabilities are increased or decreased in accordance with the input data.

The three dimension graphs which are given in Figures 13, 14 and 15 , represent the variation on output with respect to any two inputs.

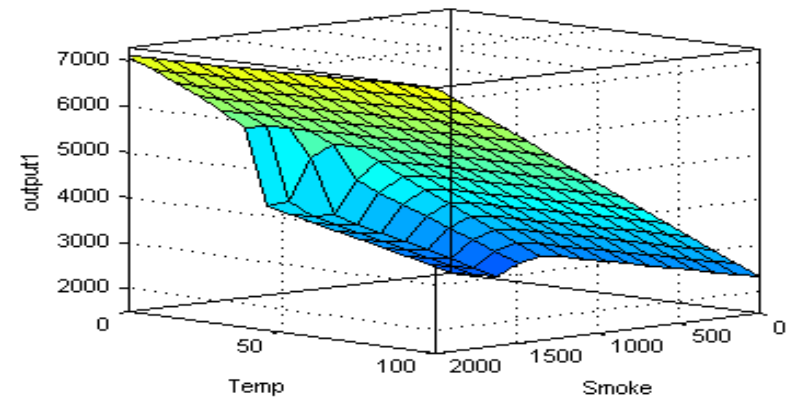

Fig 13: Effect on output with respect to Temperature and Smoke

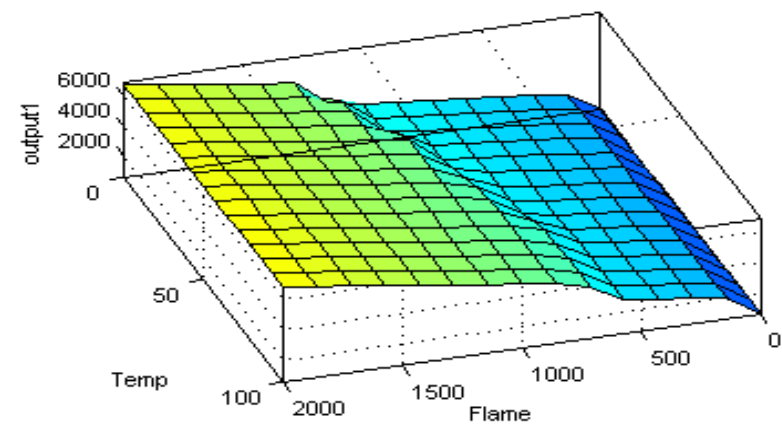

Fig 14: Effect on output with respect to Temperature and Flame

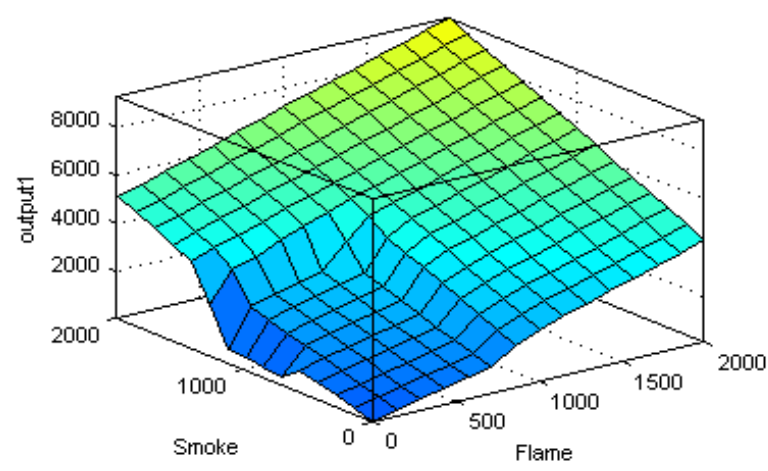

Fig 15: Effect on output with respect to Smoke and Flame

The experimental analysis is done in order to determine the effect on output values with respect to variation in any two inputs by considering the different values of fuzzy output at various input values. Based on these values, the results are analyzed, which are given below in Table 1 and 2 . From the result analysis, it can be analyzed that it is not necessary for the system to always consider the presence of all the three fire parameters for early fire detection. Whenever the value of any of the sensor starts increasing in a continuous manner, the system starts detection process. Table 1 and 2 represent the 
values of fuzzy output for different ranges of input variables flame and smoke respectively.

Table 1. Experimental Analysis in presence of Flame

\begin{tabular}{|c|c|c|c|}
\hline S. No. & $\begin{array}{c}\text { Flame } \\
\text { Detector }\end{array}$ & $\begin{array}{c}\text { Fuzzy Output } \\
\text { Status }\end{array}$ & $\begin{array}{c}\text { Fuzzy } \\
\text { Output } \\
\text { Value }\end{array}$ \\
\hline 1. & $0-50$ & No Fire & $>500$ \\
\hline 2. & $50-700$ & Potential Fire & $<1500$ \\
\hline 3. & $>700$ & Severe Fire & $<2500$ \\
\hline
\end{tabular}

Table 2. Experimental Analysis in presence of Smoke

\begin{tabular}{|c|c|c|c|}
\hline S. No. & $\begin{array}{c}\text { Smoke } \\
\text { sensor }\end{array}$ & $\begin{array}{c}\text { Fuzzy Output } \\
\text { Status }\end{array}$ & $\begin{array}{c}\text { Fuzzy } \\
\text { Output } \\
\text { Value }\end{array}$ \\
\hline 1. & $0-700$ & No Fire & $>500$ \\
\hline 2. & $700-900$ & Potential Fire & $<1500$ \\
\hline 3. & $>900$ & Severe Fire & $<2500$ \\
\hline
\end{tabular}

The experimental results were obtained by introducing fire conditions to the device using different sources i.e. smoke was created by burning a paper, flame was introduced by burning a candle and temperature was also increased by burning candle. When fire was introduced, the system sent alert notification via GSM, in the form of warning message as shown in Figure 16.

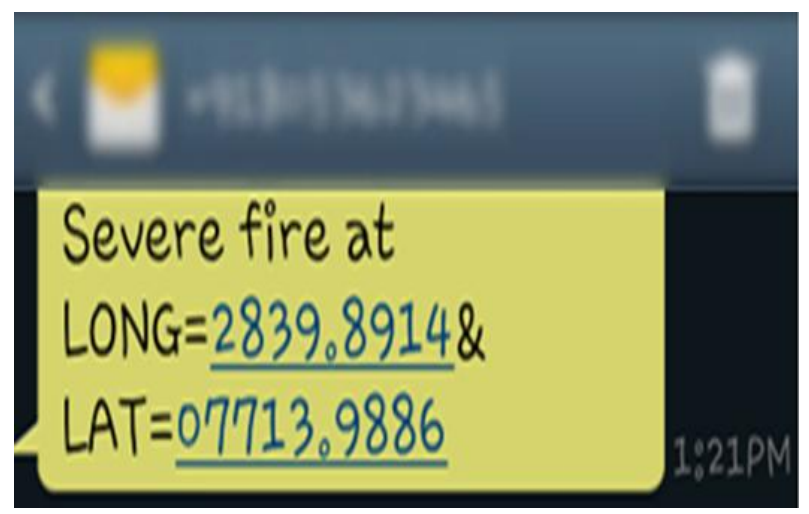

Fig 16: Screen shot of warning message

\section{CONCLUSION}

A real time fire detection mechanism with fuzzy logic implementation has been designed and developed successfully. Unlike the traditional fire detection devices, this is multi- sensor based approach and with the implementation of fuzzy logic trained by ANN, this system is able to identify the severe fire conditions and it can successfully reduce the false alarms. Experimental results show that the system gives the alert notifications only when fire conditions exist. Warning messages are transmitted only when severe fire conditions exist otherwise a buzzer is alarmed for the awareness of people.

\section{REFERENCES}

[1] R. Sowah, A. R. Ofoli, S. Krakani, S. Fiawoo, "Hardware Module Design of a Real Time Multi Sensor Fire Detection and Notification System using Fuzzy Logic,” 2014-IACC-0472, IEEE 2014.

[2] Md. I. Mobin, Md. A. Rafi, Md N. Islam, and Md R. Hasan, "An Intelligent Fire Detection and Mitigation System Safe from Fire (SFF)", International Journal of Computer Applications (0975-8887), vol. 133- no. 6, January 2016

[3] N. Alamgir, W. Boles, V. Chandran, "A Model Integrating Fire Prediction and Detection for RuralUrban Interface”, IEEE 2015.

[4] V. Khanna, R. K. Cheema, "Fire Detection Mechanism using Fuzzy Logic", International Journal of Computer Applications (0975-8887), vol. 65- no. 12, March 2013.

[5] M. Wang, H. Liu, F. Chen, J. Liu, "Forest fire warning system based on GIS and WSNs", $4^{\text {th }}$ International Conference on Advanced Information Technology and Sensor Application, DOI 10.1109/AITS, IEEE 2015.

[6] C. Caixia, S. Fuchun ,Z. Xinnquan, "One Fire Detection Method Using Neural Network", Tsinghua Science and Technology, ISSN 1007-0214, pp. 31-35, vol. 16, no. 1, February 2011.

[7] H. Wang, Y. Zhang, L. Meng, Z. Chen, "The Research of Fire Detector Based on Information Fusion Technology", International Conference on Electronic \& Mechanical Engineering and Inforamtion Technology, August 12-14, 2011.

[8] G. Jian, Z. Jie, Z. MIngru, S. Yuan, "Application of SelfAdaptive Neural Fuzzy Network in Early Detection of Conveyor Belt Fire", IEEE 2009.

[9] G. P. Jiang, F. Shang, F. Wang, X. Liu, T. S. Qiu, "A Combined Intelligent Fire Detector with BP Networks", Proceedings of the $6^{\text {th }}$ World Congress on Intelligent Control and Automation, IEEE, June21-23, 2006.

[10] C. Xiaojuan, B. Leping, " Research of Fire detection Method Based on Multi- sensor Data Fusion", IEEE, 2010.

[11] N. Cheng, Q. Wu, "A Decision- Making Method for Fire Detection Data Fusion Based on Bayesian Approach", $4^{\text {th }}$ International Conference on Digital Manufacturing and Automation, DOI 10.1109/ ICDMA, IEEE, 2013.

[12] Y. Hongyan, G. Shuqin, H. Ligang, " Research of Fire Detection System based on Zigbee Wireless Network", International Conference on Industrial Control and Electronics Engineering, DOI 10.1109/ICICEE, IEEE, 2012.

[13] R. B. Nugroho, E. Susanto, U. Sunarya, "Wireless Sensor Network for Prototype of Fire Detection", $2^{\text {nd }}$ International Conference on Information and Communication Technology, IEEE, 2014.

[14] T. Fujinaka, M. Yoshioka, S. Omatu, T. Kosaka, "Intelliogent Electronic Nose Systems for Fire Detection Systems Baseed on Neural Networks", $2^{\text {nd }}$ International Conference on Advanced Engineering Computing and Applications in Sciences, DOI 10.1109/ADVCOMP, IEEE, 2008 
International Journal of Computer Applications (0975 - 8887)

Volume 146 - No.10, July 2016

[15] B. Charumporn, T. Fujinaka, M. Yoshioka, and S. Omatu, " compact Electronic Nose Systems Using Metal Oxide Gas Sensors for Detection Systems", International Joint Conference on Neural Networks, IEEE, July 16-21, 2006.

[16] W. Lee, M. Cheon, C. H. Hyun, M. Park, "Development of building fire safety system with automatic security firm monitoring capability", Fire Safety Journal 58, Elsevier Ltd., 2013.

[17] C. C. Ho, T. H. Kuo, "Real- Time Video-Based Fire Smoke Detection Systems", IEEE/ASME International
Conference on Advanced Intelligent Mechatronics, July 14-17, 2009.

[18] T. H. Chen, P. Hsuch, Y. C. Chiou, "An Early FireDetection Method Based on Image Processing", International Conference on Image Processing, IEEE, 2004.

[19] J. Mendel, "Fuzzy Logic Systems for Engineering: a tutorial”, Proceedings of the IEEE 83(3):345-377,March, 1995. 